\title{
SILENCIOSA MÚSICA DA PROSA? O POTENCIAL DE PERFORMATIVIDADE DE A MONTANHA MÁGICA DE THOMAS MANN
}

Rafael Humberto Silveira ${ }^{1}$

RESUMO: Thomas Mann influenciou permanentemente a teoria narrativa com seu romance Der Zauberberg (A Montanha Mágica, publicado 1924) e com as considerações feitas na palestra introdutória ao romance em 1939, durante seu exílio nos E.U.A. A presente contribuição examina os argumentos centrais desse ensaio e excertos do romance para demonstrar que aspectos do texto que o autor relaciona com a música se referem mais especificamente a um potencial de performatividade da narrativa. Esse potencial é mostrado e explicado no artigo por meio de excertos do romance.

PalAVRAS-ChAVE: Thomas Mann; Der Zauberberg; Literatura e música; Performatividade narrativa; Tempo; Leitmotiv.

\section{SILENT MUSIC OF PROSE? THE POTENTIAL OF PERFORMATIVITY IN THOMAS MANN'S DER ZAUBERBERG}

ABSTRACT: Thomas Mann influenced narrative theory permanently with his novel Der Zauberberg (The Magic Mountain, published 1924) and the remarks made in his introductory lecture in 1939, during his wartime exile in the U.S.A. This article examines the main arguments of this lecture and relevant passages from the novel to demonstrate that aspects of the text related to music refer more specifically to a potential for narrative performativity. This potential is demonstrated and explained in the article using exemplary excerpts from the novel.

KEY-wORDS: Thomas Mann; Der Zauberberg; Literature and Music; Narrative Performativity; Time; Leitmotiv.

\footnotetext{
${ }^{1}$ Graduado em Germanística e Alemão como língua estrangeira, mestre em Literatura-Arte-Cultura, doutor em Literatura Alemã pela Universidade Friedrich-Schiller de Jena (Alemanha), tradutor, escritor e músico. E-mail: rafael-humberto.silveira@uni-jena.de.
} 


\section{Criação \&}

\section{Introdução: 'Música' da prosa?}

"Profunda é a fonte do passado. Não a deveríamos chamar de inescrutável?"

(MANN, 1972, p. 5) $)^{2}$

Um aspecto crucial que impossibilita o aprofundamento do estudo das origens da fala, da música e da literatura é o fato de não termos acesso direto ao universo sonoro anterior ao desenvolvimento de mecanismos de gravação e reprodução de áudio. A fonte profunda do passado dos sons é silente, porém não inescrutável: Indiretamente podemos concluir que nossos ancestrais experienciaram vários dos mesmos fenômenos auditivos que nós hoje como o bater ritmado de seus corações, os sons, por vezes repetitivos, de animais, de elementos naturais, em suma, de diversos ciclos presentes na natureza (OLSEN, 2007). Adicione-se a isso a música dos poucos instrumentos pré-históricos que sobreviveram à ação do tempo (SOUZA, 2009). Podemos também supor com alguma convicção que balbucios e gritos vieram antes da fala e do canto - como se dá, por exemplo, no desenvolvimento de crianças - e sobretudo que precederam a escrita e instrumentos musicais em geral. Não foram preponderantemente os fenômenos auditivos que se transformaram ao longo de nosso desenvolvimento, mas sim nossa capacidade de interpretá-los e categorizá-los como linguagem.

Por ser tão primeva, é difícil retraçar a relação entre música e literatura com precisão ou estabelecer linhas limítrofes para características específicas de cada âmbito. A própria escrita nasce do desejo de cultivar e transmitir ideias e sons que, a partir disso, podem continuar a ser desenvolvidos, dando origem a convenções e a uma tradição. Parece plausível, nesse sentido, que uma distinção entre música e literatura, tal como a que conhecemos hoje, possa ter se iniciado não devido a características específicas de cada âmbito, mas sim com o desenvolvimento de formas distintas de se registrar fala e canto ( $\mathrm{v}$. PERROT, 2012). O entrecruzamento primordial de música e literatura se manifesta, por exemplo, na designação de um gênero de poesia 'lírica', ou seja, outrora acompanhada pela lira, instrumento musical de cordas popular na Antiguidade clássica (HILLEBRANDT, 2017, p. 339).

Desde já é possível constatar que quando nos referimos a uma 'musicalidade' de textos usamos conceitos amplos que até o presente momento foram explorados apenas de forma tangencial pelas ciências literárias - como constata Britta Herrmann (2015, p. 10). A abordagem de alguns desses conceitos, pretendida na presente contribuição, vai exigir, portanto, uma breve introdução teórica, realizada na primeira parte deste artigo, com o intuito de esclarecer a definição e a aplicação de alguns termos básicos para a discussão da temática.

A pergunta que deu origem a esta comunicação é: a que exatamente se refere a 'musicalidade' de estruturas narrativas de que fala Thomas Mann em 1939, por ocasião de sua palestra introdutória ao romance Der Zauberberg (A Montanha Mágica) em Princeton? A segunda parte do artigo se dedicará a responder a essa pergunta, analisando a argumentação do autor e três exemplos de seu romance. Dessa análise serão então derivadas conclusões

\footnotetext{
${ }^{2}$ Excerto original - da tetralogia Joseph und seine Brüder ("José e seus irmãos") de Thomas Mann: "Tief ist der Brunnen der Vergangenheit. Sollte man ihn nicht unergründlich nennen?"
} 


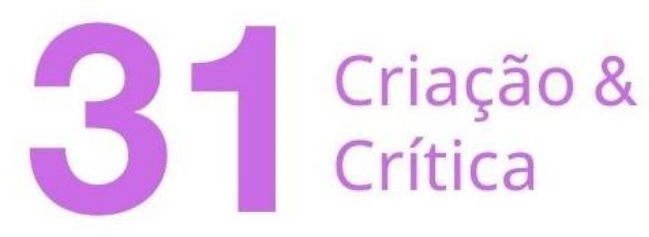

relevantes para uma melhor compreensão de aspectos da relação entre estruturas textuais e musicais, assim como da relação entre textos literários e a (performance de) sua leitura.

\subsection{Os planos estático e performático de literatura e música}

Para uma análise mais precisa e aprofundada da 'musicalidade' da prosa convém primeiramente diferenciarmos dois planos ou 'estados' dos dois âmbitos artísticos: um estático e um performático. No contexto a ser abordado, o plano estático se refere concretamente à escrita, mídia comum aos dois âmbitos e por meio da qual música e literatura podem ser registradas. Temos assim, de um lado, a música em sua forma estática (a notação musical) e em sua forma performática, p. ex. no ato de sua execução, ou seja, na performance musical; e, de outro, a literatura em sua forma escrita (texto) e em sua execução por meio da leitura, seja ela compartilhada (em voz alta) ou individual, mental - esta também comumente chamada de 'leitura silenciosa' (v. tab. 1).

\begin{tabular}{|c|c|c|}
\hline & música & literatura \\
\hline forma estática & notação musical & texto \\
\hline forma performática & performance musical & leitura \\
\hline
\end{tabular}

Tabela 1: Planos estático e performático de música e literatura.

A leitura individual constitui uma performance mental, como pontua Britta Herrmann em alusão a Aurelius Augustinus: "A escrita força os leitores, segundo Augustinus, a reproduzir o som das palavras como se as tocassem. Observar os sinais visuais faz surgir uma voz no leitor" (HERRMANN, 2015, p. 18). ${ }^{3}$ Enquanto no âmbito da literatura a leitura individual pode ser considerada a modalidade padrão, uma leitura individual de notações musicais desvinculada de uma performance posterior é incomum. Diferentemente de livros, notações musicais não são concebidas para a leitura individual silenciosa. Mesmo a leitura de reconhecimento de uma partitura muitas vezes pode ser acompanhada de vocalizações que auxiliam no reconhecimento e na percepção das relações sonoras. Além disso, é possível 'tocar' melodias ou canções que nos são familiares de modo apenas mental: conhecemos e experienciamos vez ou outra o fenômeno (chamado em alemão de 'Ohrwurm' - v. HEMMING, 2009 -, ipsis litteris uma 'minhoca de ouvido') de pensarmos em uma música ou melodia cuja repetida performance mental involuntária pode até ser percebida como irritante.

Os dois planos ou duas dimensões anteriormente apresentados podem ser comparados à diferenciação basilar de Ferdinand de Saussure entre langue e parole, no sentido de que a notação ou o texto são estáticos (como a langue ou a língua enquanto código), mas sua execução, sua performance e sua prática são dinâmicas (como a parole ou

\footnotetext{
${ }^{3}$ Todas as traduções do alemão, inglês e francês para o português brasileiro nesse artigo são minhas, R. S. Excerto original em alemão: "Die Schrift zwingt die Lesenden, so Augustinus, den Klang der Worte zu reproduzieren - ihn gleichsam abzuspielen. Das Betrachten der visuellen Zeichen lässt im Leser eine Stimme hervorbrechen."
} 


\section{Criação \&}

o uso da língua) e, portanto, singulares enquanto atos. ${ }^{4}$ Podemos considerar ainda que a dimensão estática é abstrata e ideal, já que se trata, no caso de textos e notações musicais, de uma descrição ou instrução de uma performance a ser (potencialmente) realizada de determinada forma, ao passo que a dimensão performática é concreta, constitui um ato real cronologicamente singular.

\subsection{Performance e performatividade}

Uma primeira constatação básica a ser feita da categorização apresentada é a de que textos em geral - e não apenas notações musicais, mas também praticamente todos os gêneros textuais - possuem um potencial de performance, no sentido de que podem ser apresentados ou lidos em voz alta. Esse potencial dos textos apresenta, por sua vez, um potencial de performatividade, que se refere, neste contexto, à capacidade de evocarem, induzirem ou realizarem transformações no mundo real.

O conceito de performatividade é originário das ideias de John L. Austin, que foram adotadas e adaptadas por inúmeros outros pesquisadores em Semiótica, Pragmática, Poética Cognitiva, Narratologia, dentre outras áreas (v. WIRTH, 2002, p. 9-60). Ute Berns caracteriza a 'performatividade' de narrativas como modos de apresentação ou evocação de ações (BERNS, 2009, p. 370). A autora diferencia ainda uma primeira categoria de performatividade ("performativity I"), relacionada à performance compartilhada ou, no caso de textos, por exemplo, a leitura em voz alta de determinado conteúdo, e uma segunda categoria, relacionada à representação individual, imaginária, mental ("performativity II"), como a leitura silenciosa do conteúdo de um texto (BERNS, 2009, p. 371, v. tab. 2).

\begin{tabular}{|c|c|c|c|c|}
\hline & Performatividade I.i & $\begin{array}{c}\text { Performatividade } \\
\text { I.ii }\end{array}$ & $\begin{array}{c}\text { Performatividade } \\
\text { Il.i }\end{array}$ & $\begin{array}{c}\text { Performatividade } \\
\text { Il.ii }\end{array}$ \\
\hline $\begin{array}{c}\text { Plano da } \\
\text { história } \\
\text { (story) }\end{array}$ & performance & $\begin{array}{c}\text { performance } \\
\text { imaginada /descrita }\end{array}$ & \\
\hline $\begin{array}{c}\text { Plano da } \\
\text { narração }\end{array}$ & & $\begin{array}{c}\text { performance da } \\
\text { narração }\end{array}$ & & $\begin{array}{c}\text { performance } \\
\text { imaginada da } \\
\text { narração }\end{array}$ \\
\hline
\end{tabular}

Tabela 2: Categorias de performatividade segundo BERNS, 2009. ${ }^{5}$

Berns não diferencia, entretanto, os estágios anteriores à performance, isto é, as formas estáticas da representação musical ou textual. A diferenciação dos planos estático e performático (tab. 1) revela uma primeira disparidade entre notações musicais modernas e

\footnotetext{
${ }^{4}$ A singularidade de um ato ou evento se refere nesse contexto ao fato de que mesmo que ele seja repetido, o momento de sua repetição - ou seja, sua ordem na sequência cronológica de acontecimentos no mundo real - não será o mesmo.

${ }^{5}$ A tabela 2 é uma representação minha das ideias contidas em BERNS, 2009.
} 


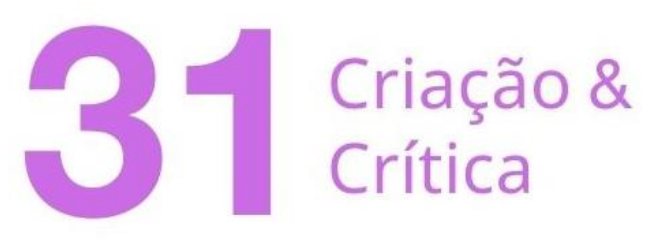

textos literários: o plano performático é enfatizado em notações musicais modernas, fato que pode ser constatado através da análise comparativa de recursos textuais relacionados à performance.

Exemplos de indicações relativas à performance presentes em notações musicais são: especificações de velocidade de execução ou de 'andamento' - em 'beats per minute' ou nos tempos musicais convencionais, como p. ex. largo, adagio, andante, allegro, presto, etc. (v. EGGEBRECHT, 1967, p. 567); 'valores' das notas ou seu tempo de duração e da duração das pausas entre elas (breve, mínima, colcheia, etc.); especificações de ritmo, ou seja, da coordenação de elementos da performance em determinada sequência de execução; tonalidade, dinâmica, intensidade ou modo de execução de um som (HERRMANN, 2015, p. 19); dentre outros.

Ao contrário de notações musicais, textos literários convencionais não possuem mecanismos desenvolvidos especificamente para a representação de aspectos relativos à performance. Eventualmente, esses aspectos podem ser indicados indiretamente, por meio, por exemplo, de comentários do narrador na prosa, de didascálias no gênero dramático ou da linguagem poética na poesia (v. HILLEBRANDT, 2017; HANNA, 2015). Essas adaptações, entretanto, apenas confirmam a inexistência de mecanismos específicos de representação gráfica de aspectos performáticos próprios de textos narrativos.

Exemplos abordados nas partes seguintes deste artigo ilustrarão esse fenômeno e ajudarão a reforçar o argumento de que o que é comumente chamado de 'musicalidade' da prosa se refere muitas vezes não a aspectos genuinamente musicais, mas sim a aspectos de um modo de escrita que enfatiza a (ou uma determinada) performance da leitura.

\subsection{0 potencial de performatividade de estruturas textuais}

Num primeiro momento, o aspecto da performance pode aparentar possuir uma relevância maior para a música, já que a notação musical em geral é utilizada apenas como recurso auxiliar da prática musical. Ou seja, não é usual lermos partituras pelo prazer de fazêlo, assim como boa parte dos leitores ${ }^{6}$ de textos literários (para adultos) provavelmente não os leem em voz alta para outras pessoas. Entretanto, através da comparação entre o estado estático dos dois âmbitos ressalta-se o fato de que todo texto é também um recurso auxiliar da performance da leitura, seja ela compartilhada (em voz alta) ou apenas mental. Textos literários cumprem sua função como tal apenas quando encontram leitores que reconstruam o conteúdo (d)escrito primeiramente individualmente e, eventualmente em um momento posterior, de forma compartilhada por meio da leitura compartilhada (em voz alta), da encenação de um texto dramático, do recitar de um poema etc. Nesse sentido, poderíamos afirmar que não existe 'leitura silenciosa', uma vez que a "voz do texto" (HERRMANN, 2015, p. 19) se manifesta como simulação cerebral de seu conteúdo, mesmo que ele não seja lido em voz alta. Textos literários apresentam, nesse sentido, um potencial de performatividade inerente e fundamental para sua interpretação, como será abordado no que se segue.

Retornando às constatações anteriores para aprofundá-las: textos possuem uma dimensão performática, no sentido de poderem ser compartilhados (lidos e/ou encenados), e uma dimensão performativa, no sentido de que sua recepção pode produzir transformações

${ }^{6}$ O termo 'leitor' é utilizado nesse artigo no sentido genérico neutro. 


\section{Criação \&}

nos leitores e, por conseguinte, no mundo real (WIRTH, 2002, p. 9, 10 e 41). Algumas dessas transformações que a leitura pode induzir em leitores se referem a mudanças de concepção, atitude, opinião, ação - como reconhecem, dentre outros, Judith Butler (1997), Victor Turner (2002), Sybille Krämer (2002), Joshua Kavaloski (2014). Entretanto, uma transformação (performativa) imediata gerada pela leitura se dá já através das dimensões de espacialidade de textos e da temporalidade da leitura.

A espacialidade textual é o meio pelo qual textos narrativos constroem sua temporalidade, que é decodificada pela leitura (STOCKER, 2015, p. 39). Quanto mais extenso um texto, ou seja, quanto maior seu número de palavras, maior será o tempo necessário para sua leitura convencional, isto é, uma leitura completa (sem se saltar partes), em um ritmo natural. O tempo exato necessário para a leitura e a velocidade individual da leitura serão sempre variáveis e de menor importância, uma vez que o objetivo da análise da leitura não é comparar velocidades individuais de forma meramente quantitativa, mas sim investigar a experiência de uma temporalidade construída por meio do ato da leitura. Portanto, se mantida dentro da normalidade do ritmo natural de cada leitor, a velocidade da leitura pode ser desconsiderada nesse contexto.

Extensão e complexidade textual são fatores concretos e mensuráveis que podem ser utilizados na análise da performatividade de textos literários. A extensão se refere ao número de palavras e aos espaços gráficos de um texto, ou seja, os espaços deixados intencionalmente também possuem um valor semântico (AUST, 1983, p. 212), devendo ser levados em consideração. A extensão textual é, de forma geral, um fator constituinte de textos que possui grande impacto em sua recepção. Ela pode, por exemplo, gerar julgamentos e inferências em relação à complexidade de uma obra mesmo antes do início da leitura.

A complexidade textual, embora ainda pouco explorada nas ciências literárias, é um critério de análise de textos consolidado no âmbito do ensino de línguas. No contexto de nivelamento para fins didáticos, complexidade textual pode se referir a aspectos:

- lexicais (como quantidade e frequência de semantemas, v. DASCĂLU, 2014);

- semânticos (como coesão e coerência textual, a utilização de neologismos, de referências culturalmente específicas, de ironia, de linguagem metafórica, poética etc.);

- sintáticos (como a utilização de estruturas frasais extensas e/ou compostas, de aposições, de tempos verbais complexos etc.);

- gráficos (como a utilização da espacialidade de caracteres, de espaços em branco etc.).

Outros aspectos não especificados no contexto do nivelamento linguístico com fins didáticos são, por exemplo, o registro (formal, informal, dialetal), o código do texto, como no caso da utilização de diferentes línguas, linguagens ou mídias. Essas são algumas das principais categorias que podem auxiliar na análise de uma possível função de estruturas narrativas, como a identificação de seu potencial performativo.

Um aspecto que não se encontra presente dentre essas categorias é o da 'musicalidade' de textos. Veremos na segunda parte deste artigo que alguns romances como A Montanha Mágica chamam a atenção para o aspecto de sua extensão e se utilizam de 


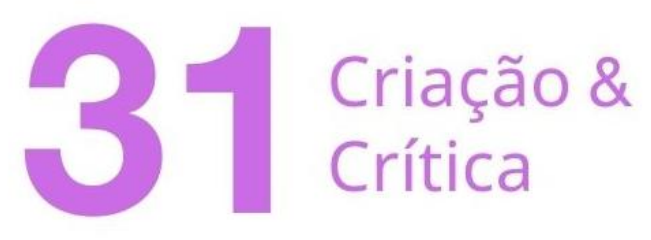

estratégias narrativas como o aumento da complexidade de cenas ou comentários metanarrativos para ressaltar a temporalidade do narrar. De forma prática, isso significa um potencial de influência na performance do texto. Um exemplo clássico da utilização dessa estratégia é o romance Life and Opinions of Tristram Shandy gentleman, de Laurence Sterne - em que o narrador, Tristram, não consegue contar sua própria história devido a inúmeros desvios temáticos devidamente comentados e ressaltados por ele mesmo (v. YAHAV, 2013).

Antes de aprofundar a questão do potencial de performatividade de estruturas narrativas, proponho analisar os argumentos da referida palestra introdutória de Thomas Mann para estabelecer uma relação entre eles e aspectos estruturais encontrados em $A$ Montanha Mágica - uma vez que na palestra o autor não cita exemplos concretos do romance. Em seguida, serão introduzidos critérios de análise dos dois âmbitos de expressão, música e literatura, que auxiliarão a compreensão dos aspectos referidos por Mann como 'simbólicos' e 'musicais'.

\section{Thomas Mann e a 'musicalidade' d'A Montanha Mágica}

\subsection{Contexto de surgimento do romance}

Dentre os grandes nomes da literatura de língua alemã, um dos autores que mais ressaltou uma 'musicalidade' de sua prosa foi sem dúvida Paul Thomas Mann (1875-1955). Em um de seus relatos autobiográficos (Lebenslauf 1936), Thomas Mann atribui suas inclinações artísticas à influência materna e ressalta em diversas ocasiões que sua mãe, Júlia Mann - nascida Júlia da Silva-Bruhns em Parati, Rio de Janeiro -, era "excepcionalmente musical" (MANN, 1990, p. 451). ${ }^{7}$ Entretanto, logo após a menção dessa característica (da musicalidade materna) o autor a relaciona ${ }^{8}$ com o "gosto por fabulações" (MANN, 1990, p. 451), que teria sido herdado por ele. Música e literatura são colocadas, assim, num mesmo patamar de prática artística cotidiana. Esse e outros exemplos a serem apresentados a seguir denotam um grau de consciência de Thomas Mann em relação ao 'fazer', ou seja, aos aspectos da ação e da interação artísticas -denominador comum dos dois âmbitos.

Publicado em 1924, A montanha mágica representa um marco não apenas para a literatura alemã moderna, como também para a teoria narrativa do século $X X$. Nomes importantes da Narratologia, como, dentre outros, Günther Müller, Gérard Genette, Paul Ricoeur e Hans Robert Jauß fazem referência a e se baseiam em aspectos delineados no romance para desenvolver suas teorias de análise de narrativas. O status alcançado pela obra se deve em grande parte ao trabalho de construção de uma estrutura narrativa que busca incorporar aspectos que o próprio autor caracteriza, em suas considerações feitas na palestra Introdução à Montanha Mágica para estudantes da universidade de Princeton (Einführung in

\footnotetext{
7 "Sie war [...] außerordentlich musikalisch." (MANN, 1990, p. 451, [Lebenslauf 1936], p. 450-456). Omissão em colchetes minha, R. S. Thomas Mann reforça essa inclinação musical de sua mãe p. ex. no outro relato autobiográfico Das Bild der Mutter (MANN, 1990, p. 420-423).

${ }^{8}$ Numa referência à penúltima estrofe de "Zahme Xenien VI" de Johann Wolfgang Goethe: "Vom Vater hab ich die Statur, / Des Lebens ernstes Führen, / Von Mütterchen die Frohnatur / Und Lust zu fabulieren." (GOETHE, 2007, p. 206).
} 


\section{Criação \&}

den 'Zauberberg' für Studenten der Universität Princeton), de 1939, como "forma simbólica da música" (MANN, 1990, p. 611).

Nessa aula introdutória durante o exílio nos Estados Unidos, Thomas Mann retraça o surgimento da inspiração para o romance e o situa na cronologia de suas outras obras. Mann havia publicado o romance Königliche Hoheit e trabalhava na concepção de Bekenntnisse des Hochstaplers Felix Krull - projeto que foi interrompido em 1913 e retomado nos últimos anos de vida do autor (1950 a 1954), mas permaneceu inacabado. Segundo o autor, A Montanha Mágica foi concebida inicialmente como 'contraparte' (em alemão "Gegenstück", MANN, 1990, p. 606) em relação a seu último romance na época, Morte em Veneza (Tod in Venedig), publicado em 1912. Pouco antes da publicação, Thomas Mann visita sua esposa Katia em um sanatório especializado no tratamento de afecções pulmonares em Davos, na Suíça, no qual ela, mesmo não estando gravemente doente, havia recebido uma recomendação médica profilática de se internar. Das impressões da visita de três semanas ao sanatório suíço surge a espinha dorsal do romance que o autor começa a elaborar em 1912 (MANN, 1990, p. 604), sendo interrompido pela eclosão da Primeira Guerra Mundial dois anos depois.

Antes de retomar A Montanha Mágica, Mann se dedica até aproximadamente julho de 1918 (BLÖDORN; MARX, 2015, p. 256) à sua obra não-ficcional mais extensa, Considerações de um apolítico (Betrachtungen eines Unpolitischen). Trata-se de uma tentativa de justificativa às acusações de isenção ideológica do autor em relação a questões polêmicas e prementes da época, como as tensões que levaram ao conflito, o posicionamento da Alemanha nesse contexto e o papel de escritores em relação a acontecimentos políticos. Mann já havia abordado algumas dessas questões em seu ensaio Pensamentos na guerra (Gedanken im Kriege), publicado na revista Neue Rundschau em novembro de 1914 (MANN, 1914), no qual se posicionava favoravelmente ao conflito. Esse ensaio gera uma reação contrária do também escritor Heinrich Mann, irmão mais velho de Thomas, e uma desavença ideológica e pessoal entre os dois. Em 1918, ao final do sangrento conflito mundial, é o romance de Heinrich, Der Untertan ( $O$ súdito), uma crítica satírica à então definitivamente falida e desmoralizada mentalidade monarquista, que mantém sua atualidade e veemência (cf. MARTIN, 2018). Nos anos seguintes, Thomas Mann procura se abster de posicionamentos ideológicos explícitos e apresenta, ao invés disso, através das personagens de A Montanha Mágica, perspectivas de diversas ideologias, interesses e conflitos do período que antecede a guerra. Parte das ideias discutidas nas Considerações de um apolítico influenciou diretamente a concepção de personagens de A Montanha Mágica (como Leo Naphta e Lodovico Settembrini) após a retomada do projeto do romance, em 1919.

O final da Primeira Guerra Mundial, o choque e a grande desilusão provocados pela derrota e pelo colapso de quatro impérios (o alemão, o áustro-húngaro, o russo e o otomano) são abordados já na introdução do romance, intitulada não de 'Vorwort' ('prefácio'), mas sim de "Vorsatz" - 'propósito' ou 'proposição' - (MANN, 2002, p. 9), palavra que, assim como a inscrição "FINIS OPERIS" (MANN, 2002, p. 1085) ao final do romance, remonta a termos comumente utilizados em notações musicais. O "Propósito" em A Montanha Mágica é um comentário metanarrativo (o primeiro de vários), ou seja, em que o narrador comenta e ressalta o próprio narrar. Já nesse primeiro comentário é introduzida também a temática do tempo: o narrador atribui ao impacto causado por transformações tão profundas e abruptas a causa da sensação de que a história a ser por ele contada teria se tornado subitamente muito 


\section{Criação \&}

mais velha do que os anos passados desde seu desenrolar (MANN, 2002, p. 9). Mann conecta em seu romance duas experiências extremamente contrastantes: de um lado a do repouso semivegetativo no refinado sanatório suíço isolado nas montanhas; de outro, a imagem do furor da eclosão da guerra. Para tanto, o autor lança mão de um narrador heterodiegético com um senso de ironia e tragicidade tão refinado quanto a erudição de várias das personagens. Os debates travados entre Hans Castorp, seu primo Joachim Ziemßen, Settembrini, Naphta e Mynheer Peeperkorn podem, assim, ser considerados um raio $X$ do período pré-guerra (NEUMANN, 2001, p. 74) - ou, como o próprio autor coloca, uma forma de reconstrução e documentação "da mentalidade europeia e das questões ideológicas no primeiro terço do século XX" (MANN, 1990, p. 602) que foram definitivamente sepultadas pelas vastas implicações do conflito.

\subsection{0 escritor 'músico'}

Na palestra introdutória de Princeton, Thomas Mann se refere, assim, não apenas à temática de $A$ Montanha Mágica, mas mais especificamente à sua estrutura, que teria, segundo ele, por princípio básico uma "suspensão do tempo" por meio da utilização da técnica (musical) do "Leitmotiv" (MANN, 1990, p. 603). Mann utiliza uma série de metáforas e comparações relativas à música, como o termo "Gegenstück" (MANN, 1990, p. 606), mencionado anteriormente, que sugere a percepção do conjunto de sua obra literária como uma grande peça sinfônica em que cada romance ou ensaio poderia ser interpretado como um movimento (em alemão 'Satz', literalmente 'frase', v. LEUCHTMANN, 2000, p. 83), como nesse trecho da palestra:

O trabalho de uma vida também possui, como um todo, seus Leitmotivs que se prestam à tentativa de criar unidade, de tornar a unidade perceptível e manter o todo presente em cada obra. [...] É, por exemplo, muito difícil e quase impraticável falar d'A Montanha Mágica sem se pensar nas relações que o romance mantém retrospectivamente - com meu primeiro romance Buddenbrooks, com o polêmico ensaio crítico Considerações de um apolítico e com Morte em Veneza assim como - prospectivamente - com [a tetralogia] José [e seus irmãos]. ${ }^{9}$ (MANN, 1990, p. 603 sq.)

O termo 'Leitmotiv' se refere originalmente a uma "figura musical pregnante associada a um elemento poético (uma ideia, coisa, pessoa etc.) e que se repete no texto musical quando tal elemento reaparece" (EGGEBRECHT, 1967, p. 512). Mann esclarece seu uso do termo em uma parte mais posterior de sua introdução: "No meu caso, tenho de me

\footnotetext{
${ }^{9}$ Excerto original: "So hat auch das Lebenswerk als Ganzes seine Leitmotive, die dem Versuche dienen, Einheit zu schaffen, Einheit fühlbar zu machen und das Ganze im Einzelwerk gegenwärtig zu halten. [...] Es ist zum Beispiel sehr schwer und fast untunlich, über den ,Zauberberg' zu sprechen, ohne Beziehungen zu gedenken, die er - rückwärts - zu meinem Jugendroman ,Buddenbrooks', zur kritischpolemischen Abhandlung ,Betrachtungen eines Unpolitischen' und zum ,Tod in Venedig und - vorwärts - zu den Joseph-Romanen unterhält." Omissões e complementos em colchetes feitos por mim, R. S.
} 


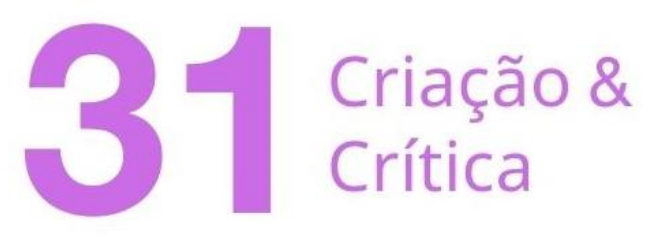

incluir aos músicos entre os escritores. O romance sempre foi para mim uma sinfonia, uma obra de contrapontos, uma trama temática na qual as ideias desempenham o papel de motivos musicais" (MANN, 1990, p. 611). ${ }^{10} \mathrm{O}$ autor afirma ter sido influenciado sobretudo pela obra de Richard Wagner ( $v$. sobre isso VAGET, 1999) e pontua mais à frente no texto que sua transposição da técnica do Leitmotiv da música para a literatura não se deu de modo naturalista - como teriam feito Émile Zola, Lev Tolstoi e o próprio Mann em Buddenbrooks -, mas sim "na forma simbólica da música" (MANN, 1990, p. 611). ${ }^{1}$

Embora Thomas Mann não esclareça a que se refere exatamente a 'forma simbólica da música', é possível deduzir de sua sugestão para que os leitores leiam o romance ao menos duas vezes que tal forma simbólica se relaciona a elementos da estrutura e da performance do texto, ou seja, de sua leitura: "Só se pode entender e desfrutar o complexo de relações musicais e de ideias formado pelo romance quando já se conhece sua temática e se pode interpretar a estrutura de forma não apenas retrospectiva, mas também prospectiva" (MANN, 1990, p. 611). ${ }^{12}$ Nesse esclarecimento, o autor aponta para os aspectos da sequência da narrativa, da repetição de elementos e da duração do narrar: conhecendo de antemão a sequência dos eventos narrados, o leitor poderia concentrar sua atenção na forma do narrar - e, por conseguinte, em sua performance da narração por meio da leitura. O próprio narrador d'A Montanha Mágica ressalta em diversos momentos aspectos do narrar no romance, como veremos nos exemplos a seguir.

\subsection{A temporalidade do narrar. Análise de excertos d'A Montanha Mágica.}

\subsection{1. "Sopa eterna e clareza repentina"}

O início do quinto capítulo do romance, intitulado "Sopa eterna e clareza repentina" (MANN, 2013), traz um comentário metanarrativo fundamental para a compreensão da referida "forma simbólica da música" (MANN, 1990, p. 611) associada por Thomas Mann à figura do Leitmotiv. Na passagem abaixo, o narrador introduz e comenta uma mudança na estrutura narrativa, mais especificamente na relação entre a extensão dos capítulos do romance e a duração dos eventos relatados.

O fenômeno que se seguirá merece a admiração do próprio narrador para que o leitor não venha a se surpreender demais com ele por conta própria. Enquanto nosso relato das três primeiras semanas da estadia de Hans Castorp junto àqueles aqui em cima (vinte e um dias de verão aos quais, segundo as previsões de meros mortais, deveria ter se limitado sua

\footnotetext{
${ }^{10}$ Excerto original: "Was mich betrifft, muss ich mich zu den Musikern unter den Dichtern rechnen. Der Roman war mir immer eine Symphonie, ein Werk der Kontrapuntik, ein Themengewebe, worin die Ideen die Rolle musikalischer Motive spielen."

${ }^{11}$ Excerto original: „in der symbolischen Art der Musik“.

${ }^{12}$ Excerto original: "Man kann den musikalisch-ideellen Beziehungskomplex, den er bildet, erst richtig durchschauen und genießen, wenn man seine Thematik schon kennt und imstande ist, das symbolisch anspielende Formelwort nicht nur rückwärts, sondern auch vorwärts zu deuten."
} 


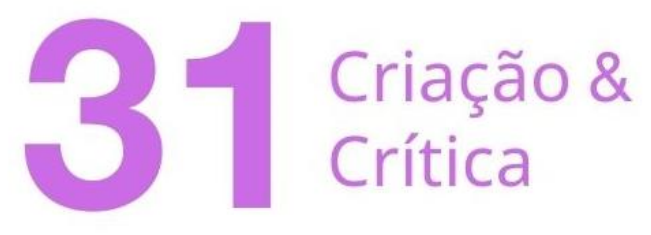

permanência) devorou quantidades enormes de tempo e espaço - cuja extensão corresponde muito bem às nossas próprias expectativas apenas parcialmente admitidas -, a superação das três semanas seguintes de sua visita a esse lugar não exigirá tantas linhas ou palavras e instantes quanto essas páginas, cadernos, horas e dias de trabalho nos custaram: num instante, como já podemos antever, essas três semanas terão sido deixadas para trás e sepultadas. (MANN, 2002, p. 279) ${ }^{13}$

Um primeiro aspecto que chama a atenção nessa passagem é sua extensão (não reproduzida em sua totalidade na citação acima): O comentário metanarrativo se estende por mais de uma página antes de o narrador retornar ao núcleo do enredo, ou seja, à trama em torno de Hans Castorp. Não se trata nesse caso de uma pausa na narração - uma vez que o narrador segue com suas reflexões sobre a forma da própria narrativa -, mas sim de uma mudança temática com implicações estéticas claras e intencionais. A primeira e mais explícita dessas implicações é o aumento da extensão do próprio texto por meio de comentários metanarrativos e de um maior detalhamento de aspectos específicos da trama (que serão comentados a seguir). Esse aumento da extensão e da complexidade é confirmado e ressaltado pelo autor na palestra de Princeton: "Esse livro cresceu espacial e intelectualmente, nesse caminho aumentativo, muito mais do que o autor originalmente com ele pretendia. A short story acabou se tornando um calhamaço em dois volumes" (MANN, 1990 , p. 612 sq.). ${ }^{14}$

Uma outra implicação estética da mudança temática sinalizada no início do quinto capítulo é o estabelecimento de uma relação entre os comentários metanarrativos e a temática do tempo (v. VAGET, 2006, p. 101). O tempo é um elemento recorrente ao longo de todo o romance e, por essa razão, mais facilmente identificável como elemento poético associado pelo autor a um Leitmotiv, ou seja, à reincidência de uma correspondência entre forma e tema no romance.

O comentário inicial de "Sopa eterna e clareza repentina" se comunica, nesse sentido, com a temática introduzida já no primeiro comentário metanarrativo, o "Propósito" ("Vorsatz"). Nele, o autor ressalta a discrepância entre diferentes tipos de manifestações cronológicas e evidencia o contraste entre a idade real dos acontecimentos contados e a sensação de que pertenceriam a um passado que, da perspectiva temporal do momento da narração (após a Primeira Guerra Mundial), pareceria muito mais remoto do que de fato era.

\footnotetext{
${ }^{13}$ Excerto original: "Hier steht eine Erscheinung bevor, über die der Erzähler sich selbst zu wundern gut tut, damit nicht der Leser auf eigene Hand sich allzusehr darüber wundere. Während nämlich unser Rechenschaftsbericht über die ersten drei Wochen von Hans Castorps Aufenthalt bei Denen hier oben (einundzwanzig Hochsommertage, auf die sich menschlicher Voraussicht nach dieser Aufenthalt überhaupt hatte beschränken sollen) Räume und Zeitmengen verschlungen hat, deren Ausdehnung unseren eigenen halb eingestandenen Erwartungen nur zu sehr entspricht, - wird die Bewältigung der nächsten drei Wochen seines Besuches an diesem Orte kaum so viele Zeilen, ja Worte und Augenblicke erfordern, als jener Seiten, Bogen, Stunden und Tagewerke gekostet hat: im Nu, das sehen wir kommen, werden diese drei Wochen hinter uns gebracht und beigesetzt sein."

${ }^{14}$ Excerto original: "Dies Buch ist räumlich und geistig auf dem Wege der Steigerung weit über das hinausgewachsen, was der Autor ursprünglich mit inm vorhatte. Aus der short story wurde der zweibändige Wälzer [...]."
} 


\section{Criação \&}

Já a discrepância cronológica ressaltada no início do quinto capítulo se refere ao ato da narração, que até esse ponto havia sido bastante detalhada em relação ao núcleo temático do romance: os primeiros três, de um total de sete capítulos do romance, cobrem - com exceção dos esclarecimentos sobre a biografia de Hans Castorp na forma de analepses no segundo capítulo - apenas o primeiro dia da estadia da personagem no sanatório. O quarto capítulo inicia com o segundo e o terceiro dias e cobre, como a passagem citada acima revela, as três primeiras semanas de Castorp na montanha - que constituíam o total originalmente planejado de sua permanência, que, entretanto, é prolongada (a um total final de sete anos) após o jovem passar por uma (leve) febre, ser examinado pelo peculiar médico da instituição, o Dr. Krokowski, e orientado por este a permanecer no sanatório.

$\mathrm{Na}$ sequência da passagem citada acima, o narrador explicita uma importante mudança no detalhamento da narrativa a partir do quinto capítulo: diferentemente das três primeiras semanas de Castorp no sanatório, que foram contadas em quatro capítulos, a narração das três semanas seguintes ocuparia muito menos espaço. Da mesma forma, os meses e (seis) anos restantes são cada vez menos detalhados cronologicamente na narrativa. O quinto capítulo cobre sete meses; o sexto, um ano e nove meses; o sétimo e último, quatro anos e meio (RICOEUR, 1984, p. 169). O narrador reforça que essa crescente discrepância corresponderia "à ordem e às leis do contar e do ouvir" (MANN, 2002, p. 279), ${ }^{15}$ entretanto retorna várias vezes ao caráter excepcional da crescente discrepância entre a relação de extensão do texto e a cronologia da história.

A dinâmica aumentativa d'A Montanha Mágica é esclarecida pelo autor em sua palestra introdutória no sentido de que a história do romance representaria um aumento, um crescimento (eine "Steigerung", MANN, 1990, p. 612) pelo qual a própria narrativa passaria: "O livro é, ele próprio, aquilo que narra. [...] A história dele [de Hans Castorp, R. S.] é uma história de crescimento e ela própria cresce como história e narrativa" (MANN, 1990, p. 612). ${ }^{16}$ Nesse sentido, o narrador explica que a mudança na forma de narrar a partir do quinto capítulo corresponderia à paulatina transformação da experiência temporal de Hans Castorp e cita o exemplo da percepção temporal de alguém febril e acamado - como é o caso do herói nessa altura da trama - que perde a noção da passagem do tempo e tem a impressão de que as refeições que lhe são trazidas se repetem como se fossem sempre a mesma "sopa eterna" (MANN, 2002, p. 279) que dá título a essa parte do capítulo. Da mesma forma, após algumas semanas de exposição à rotina repetitiva do sanatório, a percepção temporal de Castorp se aproximaria de um nunc stans (MANN, 1990, p. 621), ou seja, à ideia de um presente contínuo que, segundo o narrador, se igualaria à experiência da eternidade. Essa ideia, presente nos escritos de Tomás de Aquino que, por sua vez a atribui a Boécio, chega a Thomas Mann muito provavelmente de forma indireta, através de Friedrich Nietzsche (v. PÜTZ, 1971) e Arthur Schopenhauer. Essas alusões tornam o comentário metanarrativo ainda mais extenso e complexo, fato que nos permite interpretá-lo como um elemento de detalhamento extremo da narrativa, cuja função é simbolizar a temporalidade do próprio narrar: em comentários metanarrativos o narrador não apresenta referências cronológicas relativas à trama principal.

\footnotetext{
${ }^{15}$ Excerto original: "Dies [...] entspricht den Gesetzen des Erzählens und Zuhörens." Omissão minha, R. S.

16 "Das Buch ist selbst das, wovon es erzählt [...]. Seine [Hans Castorps, R.S.] Geschichte ist die Geschichte der Steigerung, aber sie ist Steigerung auch in sich selbst, als Geschichte und Erzählung." Omissão e acréscimo meus, R. S.
} 


\section{Criação\&}

Ao invés disso, ele enfatiza a crescente discrepância entre a temporalidade do narrar e a cronologia da história narrada, que se torna cada vez mais difícil de ser retraçada - como mostram os exemplos seguintes. 


\section{Criação \&}

\subsection{2 "Neve": extensão textual e percepção temporal}

A advertência no início do quinto capítulo d'A Montanha Mágica, que busca, segundo o narrador, "preparar [...] o leitor para o mistério temporal e outras maravilhas e fenômenos" 17 (MANN, 2002, p. 279), se aplica de forma clara a uma passagem central do sexto capítulo do romance, intitulada "Neve" ("Schnee"). De forma análoga a Hans Castorp, que se perde num passeio nas montanhas após ser surpreendido por uma nevasca e nesse contexto perde sua orientação cronológica, em "Neve" o narrador se estende num passeio por descrições extremamente detalhadas.

O detalhamento extremo da narrativa nesse capítulo é ressaltado pela surpresa de Castorp em relação ao tempo cronológico ao olhar em seu relógio: "Eram quatro e meia. Que diabos, já era quase isso quando a nevasca começou... Como acreditar que seu errar não teria durado nem quinze minutos? 'O tempo se tornou longo para mim', pensou. 'Parece que morrer é entediante.' [...]" (MANN, 2002, p. 735). ${ }^{18}$ Nessa passagem, a referência temporal relativa à cronologia da ação é introduzida não pelo narrador, mas sim pela personagem, explicitando a estratégia narrativa - mencionada anteriormente - da imersão da perspectiva temporal do narrador na percepção temporal de Castorp. Essa estratégia permite uma progressiva "suspensão do tempo" (ou "Aufhebung der Zeit"), como o autor explica em sua palestra introdutória (MANN, 1990, p. 603). Suspender o 'tempo' quer dizer, nesse contexto, tanto omitir dados cronológicos da história de Castorp quanto criar um contraste no detalhamento da narração. Por meio dessa estratégia, o leitor também perde, exatamente como o herói, a noção da duração das cenas narradas. Afinal, a surpresa da personagem em relação à duração de seu vagar se comunica nesse ponto do romance a uma quebra de expectativa em relação ao alerta feito pelo narrador no início do quinto capítulo (comentado acima em 2.3.1) sobre uma mudança do grau de detalhamento da narrativa.

O detalhamento extremo dos quinze minutos em que Castorp erra perdido na nevasca contrasta fortemente com a sucintez das passagens que sucedem esse capítulo. Esse contraste é mais um dos aspectos que podem ser identificados como 'musicais', nos termos usados pelo autor, no sentido de uma variação temática relativa ao tempo (ou, mais exatamente, à sua 'suspensão', isto é, a perda de referências cronológicas da história) acompanhada de uma mudança da forma do narrar. Também essa mudança pode ser comparada ao padrão de um Leitmotiv na música. No texto literário ela é identificável através da correspondência estabelecida no romance entre as esferas temática (com o tema 'tempo' tanto em sua essência quanto em relação à sublimação das referências cronológicas do texto) e formal (metanarração, como no caso de "Sopa eterna e clareza repentina" ou o aumento da complexidade do texto, como no caso de "Neve"). Na seção seguinte será abordado um exemplo em que essa correspondência resulta da combinação das duas estratégias.

\footnotetext{
${ }^{17}$ Excerto original: "[...] den Leser in Ansehung des Zeitgeheimnisses auf noch ganz andere Wunder und Phänomene [...] vorzubereiten." Omissões minhas, R. S.

${ }^{18}$ Excerto original: "Es war halb fünf. Was Teufel, so viel war es beinahe schon gewesen, als das Wetter losgegangen war. Sollte er glauben, dass sein Herumirren kaum eine Viertelstunde gedauert hatte? 'Die Zeit ist mir lang geworden', dachte er. 'Das Umkommen ist langweilig, wie es scheint."'
} 


\section{Criação \&}

\subsection{3 "Passeio na praia": metanarração e complexidade textual}

"Passeio na praia" (“Strandspaziergang”), início do sétimo capítulo, é, assim como o capítulo "Neve", um dos pontos centrais d'A Montanha Mágica. Nessa passagem, o narrador mais uma vez interrompe a história de Hans Castorp com um comentário metanarrativo relativo à temática do tempo associada ao narrar e, desta vez, também à música:

Será possível narrar o próprio tempo, como tal, em si mesmo? Certamente não, seria um descabimento! Uma história que contasse: "O tempo passou, escorreu, fluiu" e assim em diante, não poderia ser chamada de história. Seria como segurar o mesmo acorde alucinadamente por uma hora e chamar o resultado de música. Pois histórias se assemelham à música por preencherem o tempo, por "ocupá-lo de forma respeitável", por "dividi-lo" e fazer com que "haja algo" ou "aconteça algo" nele [...]. O tempo é o elemento das histórias como é o elemento da vida - ligado indissociavelmente a elas como aos corpos no espaço. Ele é também o elemento da música, que mede e estrutura o tempo e o torna subitamente interessante e precioso. $\left(\right.$ MANN, 2002, p. 816) ${ }^{19}$

Após a introdução desse excurso temático - a princípio completamente dissociado da história de Hans Castorp -, o narrador diferencia categorias de tempo com base na comparação feita entre narrativa e música. O tempo da música equivaleria ao tempo 'real' (MANN, 2002, p. 816) - que se refere, na realidade, ao tempo cronológico (dos relógios e calendários), como é possível inferir de outras partes do texto, como o capítulo "Neve". A narrativa disporia, segundo o narrador, de duas formas de tempo: uma "musical-real" ("musikalisch-reale") e outra de seu conteúdo (MANN, 2002, p. 817 aqui e no que se segue). Ele ressalta que, diferentemente da música, em que uma valsa intitulada "Valsa de cinco minutos" dura efetivamente cinco minutos, na narrativa os tempos mencionados tanto podem coincidir quanto divergir enormemente. Nesse sentido, a literatura possuiria, ainda segundo o narrador, a capacidade de configurar, de moldar o tempo narrado, como os sonhos. O tempo poderia, inclusive, ele mesmo constituir o tema da história, como no caso não apenas da referida passagem metanarrativa em "Passeio na praia", mas também do romance $A$

\footnotetext{
${ }^{19}$ Excerto original: "Kann man die Zeit erzählen, diese selbst, als solche, an und für sich? Wahrhaftig, nein, das wäre ein närrisches Unterfangen! Eine Erzählung, die ginge: 'Die Zeit verfloss, sie verrann, es strömte die Zeit' und so immer fort, - das könnte gesunden Sinnes wohl niemand eine Erzählung nennen. Es wäre, als wollte man hirnverbrannterweise eine Stunde lang ein und denselben Ton oder Akkord aushalten und das - für Musik ausgeben. Denn die Erzählung gleicht der Musik darin, dass sie die Zeit erfüllt, sie 'anständig ausfüllt', sie 'einteilt' und macht, dass 'etwas daran' und 'etwas los damit' ist. [...] Die Zeit ist das Element der Erzählung, wie sie das Element des Lebens ist, - unlösbar damit verbunden, wie mit den Körpern im Raum. Sie ist auch das Element der Musik, als welche die Zeit misst und gliedert, sie kurzweilig und kostbar auf einmal macht [...]."

Marcações em itálico como no original. Omissões minhas, R. S.
} 


\section{Criação \&}

Montanha Mágica como um todo, como em seguida conclui o narrador (MANN, 2002, p. 818). Dessa constatação é derivado um jogo de palavras com o atributo 'Zeitroman' ('romance de época'), aludindo ao seu significado literal como 'romance de/do tempo'. A Montanha Mágica seria, assim, um romance de época (em alemão, também 'Zeitroman'), um romance temporal, isto é, sobre o tempo como temática (da ontologia e percepção temporal, como em "Gedankenschärfe" ou "Clareza mental", no terceiro capítulo, MANN, 2002, p. 101 sqq.) e um romance de tempo, no sentido da utilização de uma estratégia narrativa que 'produz' mais tempo de leitura.

O comentário metanarrativo no início do sétimo capítulo se assemelha, assim, aos exemplos anteriores como estratégia de representação da temporalidade do narrar, porém a ele é adicionado um elemento de metalinguagem: a ideia de ser possível se narrar o tempo em si mesmo, que no começo do comentário havia sido apresentada como um "descabimento", é revelada como o verdadeiro intuito do narrador: "De fato, perguntamos se é possível narrar o tempo apenas para confessarmos que é de fato o que pretendemos com a presente história" (MANN, 2002, p. 818) ${ }^{20}$. Essa afirmação ou 'confissão', como coloca o narrador, é crucial para a compreensão da estrutura narrativa d'A Montanha Mágica. Por meio dela, a pergunta que introduz o sétimo capítulo (sobre a factibilidade de se narrar o próprio tempo) é afirmada tanto explicitamente, através da última passagem citada acima, quanto de maneira performativa, já que o 'tempo' (ou, mais precisamente, a duração) do narrar é implementado pela própria leitura. 'Narrar o tempo' significaria, portanto, estender o que o narrador categoriza como "tempo musical-real" (MANN, 2002, p. 817) por meio de comentários metanarrativos - que, por sua vez, abordam a temática do tempo e da percepção temporal reiteradamente de forma semelhante a um Leitmotiv, ou seja, na "forma simbólica da música" (MANN, 1990, p. 611).

\section{Conclusão}

Como a análise da palestra introdutória de Thomas Mann para estudantes de Princeton em 1939 e dos exemplos apresentados na presente contribuição indicam, o aspecto de 'musicalidade' da prosa em A Montanha Mágica se baseia em estratégias narrativas comparáveis a estruturas e figuras musicais, como o Leitmotiv, ressaltado pelo próprio autor (MANN, 1990, p. 611). À figura musical do Leitmotiv podemos associar a temática do tempo, que é comentada prevalentemente em passagens metanarrativas no início de capítulos do romance, como o quinto, o sexto e o sétimo capítulos. Essa comparação permite ainda a associação de diferentes obras do autor em que a temática é abordada, como, de forma mais explícita e reflexiva, em Joseph und seine Brüder (1943) e Doktor Faustus (1947), mas também de forma indireta já em Buddenbrooks (1901) e Tod in Venedig (1911).

A análise dos exemplos d'A Montanha Mágica mostra que o aumento gradual da extensão e da complexidade dos comentários metanarrativos a cada capítulo do romance possui uma função estética mencionada pelo autor em sua palestra introdutória (MANN, 1990, p. 612). Esse aumento possui o potencial de influenciar diretamente a performance da leitura

20 "Tatsächlich haben wir die Frage, ob man die Zeit erzählen könne, nur aufgeworfen, um zu gestehen, dass wir mit laufender Geschichte wirklich dergleichen vorhaben." 


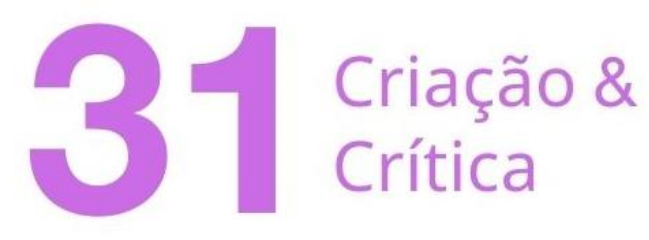

e a percepção temporal do próprio leitor que, assim como o herói, pode perder os referenciais cronológicos em passagens como "Neve" e "Passeio na praia". Essa dinâmica é chamada pelo autor de "suspensão" ("Aufhebung”) do 'tempo' (MANN, 1990, p. 603), o que, na realidade, se traduz como uma suspensão da cronologia da história. Cabe aqui um brevíssimo adendo teórico final sobre essa problemática terminológica.

As reflexões narratológicas e comparatísticas presentes nessa passagem metanarrativa ocuparam e influenciaram alguns dos principais teóricos da literatura do século XX, como Günther Müller, que adota categorias semelhantes às implementadas no romance de forma quase literal e legitima teoricamente a separação entre "Erzählzeit" ou "tempo do narrar", e "erzählte Zeit" ou "tempo narrado" (MÜLLER, 1974, p. 276). O problema terminológico criado por essa adoção é que ela se baseia no jogo de palavras com o termo 'tempo', utilizado de forma recorrente ao longo d'A Montanha Mágica. O que é reconstruído através da (meta)narração não é o tempo (cronológico, mensurável) em si, nem um 'tempo narrado', como o narrador d'A Montanha Mágica descarta ironicamente (MANN, 2002, p. 816), mas sim a duração da performance da leitura. Para a composição do romance era conveniente (e legítimo, visto não se tratar de um ensaio acadêmico) chamar essa duração (além de outros fenômenos abordados na história) simplesmente de 'tempo', reforçando, assim, o aspecto de uma recorrência gráfica, verbal e temática, como um Leitmotiv musical.

A polissemia do termo criou, entretanto, um desafio para a teoria narrativa, reconhecido mais tarde por, dentre outros, Gérard Genette, que ressalta o fato de que Müller compara a duração de um ato real (o da leitura), que pode ser medido cronometricamente (em segundos, minutos etc.), com especificações textuais abstratas que muitas vezes não são confiáveis ou nem sequer fornecidas pelo narrador (GENETTE, 2007, p. ex. p. 81, 168, 314). Genette aponta para uma substituição do termo 'tempo do narrar' por 'temporalidade' (em francês "temporalité", GENETTE, 2007, p. 22 e 314), porém sem aprofundar teoricamente seus questionamentos. A problemática é retomada mais tarde, nos anos 1980, por Paul Ricoeur (1984, p. 113-120), porém de forma igualmente infrutífera, visto que Ricoeur, assim como Genette, adota a terminologia de Müller para sua análise.

O enfoque no aspecto da performance do narrar se revela, assim, fundamental para uma possível e necessária reformulação da terminologia atual que trata das relações temporais em textos literários. O romance $A$ Montanha Mágica, que já serviu de inspiração para o batismo de uma categoria narratológica (a do "Zeit-Roman", v. JAUSS, 1986, p. 11), pode servir de base para mais esse incremento teórico. A análise de uma 'musicalidade da prosa', ou seja, de aspectos estruturais de narrativas que apresentam paralelos em relação à música é um caminho promissor e extremamente profícuo nessa direção.

\section{Referências}

AUST, Hugo. Lesen. Überlegungen zum sprachlichen Verstehen. Tübingen: Max Niemeyer, 1983.

BERNS, Ute. "Performativity". In: HÜHN, Peter [et al.]. Handbook of Narrativity. Berlim [et al.]: de Gruyter, 2009, p. 370-383.

BLÖDORN, Andreas; MARX, Friedhelm (eds.). Thomas Mann Handbuch. Stuttgart: J. B. Metzler, 2015. 


\section{Criação \&}

BUTLER, Judith. Excitable Speech. A Politics of the Performative. New York; London: Routledge, 1997.

DASCĂLU, Mihai. Analyzing Discourse and Text Complexity for Learning and Collaborating. A Cognitive Approach Based on Natural Language Processing. Dordrecht [et al.]: Springer, 2014.

EGGEBRECHT, Hans-Heinrich (ed.). Riemann Musik Lexikon. Sachteil. Mainz: B. Schotts Söhne, 1967.

GENETTE, Gérard. Discours du récit. Essai de méthode [et Noveau discours du récit (1983)]. Paris: Éditions du Seuil, 2007.

GOETHE, Johann W. Gesammelte Werke. Sankt Gallen: Otus, 2007.

HANNA, Patrizia Noel Aziz. "Pause versus Stille." In: HERRMANN, Britta (ed.): Dichtung für die Ohren. Literatur als tonale Kunst in der Moderne. Berlim: Vorwerk 8, 2015, S. 67-84.

HEMMING, Jan. Zur Phänomenologie des „Ohrwurms“. Musikpsychologie. Göttingen, v. 20., p. 184-207, 2009. Disponível em:: https://www.psycharchives.org/handle/20.500.12034/2571 Acesso em 12/08/2021.

HERRMANN, Britta (ed.). Dichtung für die Ohren. Literatur als tonale Kunst in der Moderne. Berlim: Vorwerk 8, 2015.

HILLEBRANDT, Claudia. "Lyrik als akustische Kunst." In: GESS, Nicola; HONOLD, Alexander: Handbuch Literatur und Musik. Berlim; Boston: De Gruyter, 2017, p. 338-349.

HINDRICHS, Gunnar. "Sprache und Musik." In: GESS, Nicola; HONOLD, Alexander: Handbuch Literatur und Musik. Berlim; Boston: De Gruyter, 2017, p. 19-38.

JAUSS, Hans Robert. Zeit und Erinnerung in Marcel Prousts À la recherche du temps perdu: ein Beitrag zur Theorie des Romans. Frankfurt a. M.: Suhrkamp, 1986.

KABLITZ, Andreas. Der Zauberberg. Die Zergliederung der Welt. Heidelberg: Winter, 2017.

KAVALOSKI, Joshua. High Modernism. Aestheticism and Performativity in Literature of the 1920s. Rochester; New York: Camden House, 2014.

LEHNERT, Herbert. "Introduction.” In: LEHNERT; Herbert; WESSELL, Eva: A Companion to the works of Thomas Mann. New York; Suffolk: Camden House, 2004, p. 1-28.

LEUCHTMANN, Horst. Wörterbuch Musik. Englisch-Deutsch. Dictionary of Terms in Music. English-German. Stuttgart; Weimar: J. B. Metzler, 2000.

MANN, Thomas. Der Zauberberg. Roman. Große kommentierte Frankfurter Ausgabe. Bd. 5.1. Frankfurt a. M.: S. Fischer, 2002.

MANN, Thomas. Einführung in den ,Zauberberg für Studenten der Universität Princeton (1939). In: Gesammelte Werke in dreizehn Bänden. Bd. XI. Reden und Aufsätze 3. Frankfurt a. M.: Fischer, 1990, S. 602-617.

MANN, Thomas. A Montanha Mágica. Tradução de Herbert Caro. Rio de Janeiro: Nova Fronteira, 1980.

MANN, Thomas. Joseph und seine Brüder. [Erster Band. Die Geschichten Jaakobs. Der junge Joseph.] Berlim; Weimar: Aufbau Verlag, 1972. 


\section{Criação \&}

MANN, Thomas. "Gedanken im Kriege.” Die Neue Rundschau. Band 25. Berlim: Fischer, 1914.

MARTIN, Ariane. "Zwischen den Brüdern. Arthur Schnitzler und die Konstellation um Heinrich und Thomas Mann im Jahr 1918." Literaturkritik. n. 11. Schwerpunkt: Literatur, Wissenschaft und Revolution 1918. Disponível em: https://literaturkritik.de/zwischen-bruedern-arthurschnitzler-konstellation-um-heinrich-thomas-mann-1918,25062.html. Acesso em 08/08/2021.

MÜLLER, Günther. Morphologische Poetik. Gesammelte Aufsätze. Tübingen: Max Niemeyer, 1974.

NEUMANN, Michael. "Die Irritationen des Janus oder „Der Zauberberg" im Feld der klassischen Moderne." Thomas Mann Jahrbuch, Frankfurt a. M., v. 14, p. 69-85. Disponível em: https://www.jstor.org/stable/24744144. Acesso em 03/01/2021.

OLSEN, Dale A. "The Complementarity and Interdisciplinarity of Archaeomusicology: An Introduction to the Field and This Volume." The World of Music, v. 49, n. 2, 2007, p. 11-15. Disponível em: www.jstor.org/stable/41699761. Accesso em 11/08/2021.

PERROT, Sylvain. "Le sifflement du serpent: $d u$ son inarticulé à la mise en musique." Anthropozoologica, Paris, v. 47, n. 1, 2012, p. 345-361. Disponível em: https://halshs.archives-ouvertes.fr/halshs-01632650/file/az2012n1a11.pdf. Acesso em $19 / 08 / 2021$.

PÜTZ, Peter. "Thomas Mann und Nietzsche." In: : Thomas Mann und die Tradition. Frankfurt am Main: Athenäum, 1971, p. 225-259.

RICOEUR, Paul. Temps et récit. Tome II. Paris: Seuil, 1984.

SOUZA, Jonathan de. "Voice and Instrument at the Origins of Music". In: Current Musicology, v. 97,2014 , p. 21-36. Disponível em: https://journals.cdrs.columbia.edu/wpcontent/uploads/sites/13/2016/08/CM97_DeSouza.pdf

STOCKER, Günther. '“Aufgewacht aus tiefem Lesen.' Überlegungen zur Medialität des Bücherlesens im digitalen Zeitalter." In: HERRMANN, Hans-Christian; MOSER, Jeannie (eds.): Lesen. Ein Handapparat. Frankfurt a. M.: Vittorio Klostermann, 2015, p. 33-47.

VAGET, Hans Rudolf. Seelenzauber. Thomas Mann und die Musik. Frankfurt am Main: S. Fischer, 2006.

VAGET, Hans Rudolf. Im Schatten Wagners. Thomas Mann über Richard Wagner. Texte und Zeugnisse 1895-1955. Frankfurt am Main: Fischer, 1999.

WIRTH, Uwe (ed.). Performanz. Zwischen Sprachphilosophie und Kulturwissenschaft. Frankfurt am Main: Suhrkamp, 2002.

YAHAV, Amit. "Sonorous Duration: Tristram Shandy and the Temporality of Novels." PMLA, Cambridge, v. 128, n. 4, p. 872-887, Out. 2013. Disponível em: https://doi.org/10.1632/pmla.2013.128.4.872. Acesso em 08/08/2021.

Recebido em: 29/08/2021

Aceito em: 28/10/2021

Referência eletrônica: SILVEIRA, Rafael Humberto. Silenciosa música da prosa? O potencial de performatividade de A montanha mágica de Thomas Mann. Criação \& Crítica, n. 31, p., dez. 2021. Disponível em: <http://revistas.usp.br/criacaoecritica>. Acesso em: dd. mm. aaaa 